\title{
Experiential Learning Laboratories In Business Schools: The WD-40® For Curriculum Innovation
}

Karen E. Boroff, Seton Hall University, USA Elven Riley, Seton Hall University, USA

\begin{abstract}
The authors present a case analysis of how a business school brought about curriculum innovation. The school used something borrowed, specifically experiential learning laboratories, and something new to attain measureable curriculum change, with only modest investments. The authors urge that the nimbleness of a medium-size school committed to personal touch and with a strong bias to transform concepts into practice can have a natural advantage in providing unique learning experiences, compared to a highly leveraged program encumbered by size. These learning laboratories translate to experiential learning opportunities that are more like apprenticeships and professional mentoring. Given the difficult labor market, schools that can develop demonstrable job competencies in their coursework for students will add value as these students immediately seek employment and, more broadly, develop their career paths.
\end{abstract}

Keywords: Learning Laboratories; Experiential Learning; Curriculum Innovation; Business Schools

\section{INTRODUCTION}

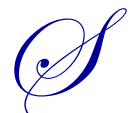

ay the words "curriculum reform" and university administrators and faculty members will have already lost the debate. However, one does not need utter these words or create grand strategic curriculum plans involving hours of stakeholder meetings to precipitate significant curriculum change (Dewey, 1938; Tyler, 1949). Instead, an institution can nonetheless reform and indeed transform its curriculum by building learning laboratories. Our case centers on building several learning laboratories at the Stillman School of Business at Seton Hall University. These laboratories include the Trading Room, the Sports Polling Center, the Center for Entrepreneurial Studies, and the Market Research Focus Group Room. As we reflect back on these initiatives, the first of which began in 2004, we have come to dispel several myths that unfortunately can paralyze organizations from taking on meaningful and needed curriculum innovations. In this paper, we discuss these myths and pose several important "musts" as we share what we learned from our experience.

We first borrow a page from our colleagues in Arts and Sciences. These colleges have a tradition to build state-of-the-art buildings that contain special purpose experimentation rooms called laboratories. This is not some blind calcified commitment to tradition, but a deep understanding that the skills acquired in translating concepts into practice can only be experientially acquired (Aldous, 2012; Hubball \& Gold, 2007; Lester \& Cole, 2009; Mangan, 2012; Summers, 2012). The skills of doing are powerful integrators of learned concepts and facts and produce minds capable of extending the academic body of knowledge as well as the commercial intellectual property captured in a corporate patent. Students thereby learn the "how" of a given task and, in so doing, can also think about the "why" of their work. These, and other questions, can help students discern whether a given course of study is suited to them long before the weight of the investment of time and money practically eliminates an opportunity to change majors.

Is the acquisition of experientially acquired skills unique to science, or is it that business schools have been timid in claiming the need for experiential skill acquisition? We believe that where the energy of business is most 
exciting and intrinsically and extrinsically rewarding is the place that brings the body of knowledge to life with the use of these very same experiential skills (Kolb \& Kolb 2005). We believe that the academic use of business labs is as engaging as the creativity required for successful enterprise leadership. In our own transformation, we have come to realize that we, too, had to dispel some of the myths that, at first blush, we thought had to be in place for curriculum change to happen. Had we not challenged these myths, we could have stymied ourselves in creating what has become a more vibrant business curriculum and student experience.

\section{The Myths}

Myth \#1

"You need faculty buy-in for any curriculum change, and especially if you want to build something physical to help it along" (Wolf, 2007). The subtext here is that unless there is some form of school-wide consensus vote by the official faculty governance group, or even at the department level, "change ain't happening." It is true that a school does need a core of faculty members who are passionate about their field and are willing to research, experiment, and engage as a normal every day behavior. This core group needs to "know what it is talking about"; that is, what is considered knowledgeable and credible about the experiential learning phenomenon that it seeks to introduce, along with the communication skills, to share these ideas with peers. In terms of organizational power, this core derives its strength to move based on its command of the knowledge base to be learned (as opposed to taught); if the core faculty group is also respected and admired by the student population as well as their peers, all the better. Naysayers and pessimists will always be present in every group and their voice should be encouraged when contributing sideways thoughts and ignored when restricted to negative emotions. The majority of faculty members are what we found to be "silent watchers", willing to give space to the innovator and, if the innovation succeeds, become subsequent supporters of the reform.

Myth \#2

"Curriculum reforms take years to see any change take place." Following this myth to its logical end, the question that follows is, "why bother with anything that takes a long time to see results? (Hlebowitsh, 1978; Lindquist, 1978). Yes, patience will always be a virtue, but today's internet generation adopts and adapts to change quickly and a young-hearted faculty "just does it" (Barnes, Marateo, \& Ferris, 2008). In fact, with the Trading Room, we observed that change happened in two years. Why? Once the room was opened, we properly suspected that the rising seniors, who were already moving on, would not invest heavily in the new learning laboratory. The juniors were curious and tentative. The incoming freshmen, not knowing anything, walked into the Trading Room as if they owned it. As far as they were concerned, this laboratory "was always there." They began to tinker with the computers and the data feeds. Likewise, the sophomores started using the space as well. Within two years, the school reached its tipping point - when a majority of students were comfortable going into the Trading Room, using the real-time NYSE feeds, participating in workshops, taking courses in the room and otherwise engaging themselves and the faculty about how the room could enhance their learning. In turn, once other faculty groups saw the success of one of these learning centers, momentum began to build for the faculty in several other disciplines to build something similar for its students. Faculty in sport management, entrepreneurship, and marketing saw the potential and moved forward.

Myth \#3

"Larger schools, with their economies of scale, will always have a cost-scale advantage for learning laboratories" (Reder, 2010). It is true that a larger school may well have a "cost per pupil" ratio about which a smaller scale would be envious. However, a smaller school has a greater degree of dexterity to bring about change. Smaller schools typically have their faculty more involved with alumni and donors, which can make those who may potentially invest in a venture more likely to see the passion, the enthusiasm, and the will to make a learning environment better (Chaffee, 1984). In addition, larger schools with their larger need for space and needs driven by a larger student population, have to find larger physical footprints to build learning laboratories. In turn, then, the break-even point for a larger construction project is that much more difficult to achieve in the near term, all else equal. Besides the need for a larger space and the higher break-even costs, larger facilities may be harder to convert 
to some other space in the future. Technology improvements and trends in the discipline are only two of the many factors that may cause a state-of-the-art room of today to become obsolete six or seven graduating classes later. Smaller spaces are easier to convert to other functional rooms later - there is just less to retrofit with regard to heating, ventilating, air conditioning, lighting, security, furnishings, and the like.

Myth \#4

"A particular laboratory will be used only by the students of that discipline." When we first built the Trading Room, there was a concern that perhaps only the finance students would use the facility. Our concern was set aside when accounting faculty and students made use of the room's resources. Students who had an interest in investing formed the Investment Club, and these members included students from all over campus - and not just business students. If faculty wanted to obtain data about firms for courses in business strategy, as an example, the Bloomberg terminal provided quick and reliable access. A course specifically designed for the Sports Polling center had appeal to students in marketing who wanted to learn more about direct marketing. Likewise, students from all disciplines who wanted to earn extra income found that working on sports polls gave them easy access to a job, which, in turn, boosted their credentials in dealing with the public. Marketing students enjoyed using the Market Research Focus Group Room as small businesses in South Orange (the home of Seton Hall University) wanted to find ways to market to college students; but our students in entrepreneurship wanted to learn more about small businesses. We also found that work-study students were able to improve their information technology skills. By keeping rooms operational, they had to know "how things worked", so this provided our colleagues in information systems an avenue of learning for their students. In addition, with so many students seeking second concentrations and minors, students were no longer "just" finance or marketing students. In all, we found that by keeping oneself porous to the opportunities that a lab presented, one could easily enlarge those that benefitted from the facility (Corbett, 2005). One will most likely find, as we did, that our students are not as siloed into disciplines and appreciate a multi-disciplinary examination of issues (Barnes, Marateo, \& Ferris, 2008).

\section{The Musts}

As we constructed the different learning laboratories, we also developed a roster of "musts." These were the guardrails that helped us stay on course for attaining the results we were discovering as we went along. To encourage change is to be open to a broad horizon of options and, at times, run the risk of analysis paralysis. To combat the wandering pointless debate, we found some core "musts" that helped us discern the change that was supportive of our existing programs from the changes that were distracting and, sometimes, destructive options.

\section{Musts \#1 and \#2}

For us, the first two "musts" reflected back and forth on each other. These were to:

1. $\quad$ specify "fitness for use" criteria for each lab

2. pass an "outside the university" practitioner evaluation

First, whatever the innovation, it has to be one that supports a school's values and strategies, ultimately bringing it back to the curriculum. Here at the Stillman School, we value small class sizes. What we call our faculty/student "ratio of touch" is important to preserve. We also value transforming concepts into practice. So, as an example, while our Trading Room team visited several trading rooms at colleges, we discarded the ones that were huge. Long rows of desks oriented in a typical lecture fashion were models that did not support our larger strategies. We wanted a smaller scale room with a physical set-up that would mirror what our student would eventually experience in the trading room of any brokerage house (the "practitioner evaluation"). Just like a chemistry laboratory, the business laboratories do not look or feel like classrooms. They are different. Certainly, any team of academicians requires some encouragement to augment the classroom paradigm with the laboratory paradigm.

So, before any sheet rock is torn down, think about not only what the room will contain, but also how the physical design of the room is congruent with a school's persona. Questions one might ask are: 
- What are the curriculum changes envisioned to utilize the laboratory space?

- How do the learning exercises and experiences of the laboratory connect and support the core learning points of the curriculum?

- What is the intended use of the facility and is this design fit for that purpose?

- $\quad$ Are pedagogical techniques that are needed in a laboratory different from even a small lecture or seminar class? If so, how will the faculty be developed to meet these new techniques?

Answering these questions for ourselves resulted in the following. For our Sports Polling Center, we wanted students to sense the busyness of a call center - to see one another making calls. That resulted in designing a unique "S" shape to the bank of positions. We also wanted them to appreciate the technology of a call center, giving them a marketable competency. The Center for Entrepreneurial Studies had to convey nimbleness in the space, telegraphing to students that entrepreneurs have to likewise be nimble. In turn, the furniture was modular, easy to move around, and the technology was such that any part of the room could be "the front." The oversized white boards helped students map out their ideas in easy brainstorming fashion. The space itself had to be welcoming to practitioners who would frequently be visiting and consulting with students. In all, schools have to invest a fair amount of time in thinking about who is going to use the space - students, faculty, practitioners - and how. This clarity of thought will help keep the "wish list" for the room in check.

Second, once confident that the curriculum points can be brought to the laboratory, we then had to ask ourselves, "Would a practitioner currently employed in the field recognize the utility of the space?" Our chemistry laboratory is designed to bring the textbook and blackboard knowledge into the physical world. So, too, should a Wall Street trader or a Park Avenue market researcher, or a Main Street political pollster be able to recognize the functional advantage of the space. The faculty may be outstanding leaders and educators but may not have as robust, or as current, "outside of academe" professional experiences. Including representation from industry advisors on several building projects guided each laboratory construction in directions we were not expecting nor in our comfort zones, but the results were undeniable.

\section{Must \#3}

Without a doubt, in order to see the learning laboratory to completion, there must be a person in charge with excellent project management skills and one who can also be a boundary spanner among the faculty, the practitioners, and the construction personnel (Tushman \& Scanlan, 1981). For the Stillman School, the faculty appointed a practitioner, but assigned him to a faculty line residing in a specific department. This part-time faculty position - about 20 hours per week for the calendar year - was a new job and unique for the School and was fully supported by the dean. The job did not require the person to teach (he subsequently did and has earned several Teaching Commendation awards), but he was literate in how a university operates. He was required to be the person who could operationalize curriculum and practitioner needs into building designs. This helped ensure that the "design-build" of all of our projects kept true to the academic needs of the faculty and meshed with our practitioner considerations. Beyond that, the person who was responsible had tremendous experience in industry on construction projects, which helped immeasurably in working with the university's building department and with outside contractors. Budgets were kept in line and projects on schedule. The person had ready access to the dean and would advise her when she had to escalate an issue, when something was off track, or when bills needed to be paid. As an example, the project manager told the dean that, for the Market Research Focus Group Room, the facilities personnel wanted to mount a $\$ 250,000$ air conditioning unit on the roof to satisfy air flow concerns. On a serendipitous walk from the parking lot to the building the next day, the dean happened to meet up with the head of construction. She said to the person, "You really have to find another solution - our students need this facility, but it would be an outrageous use of their tuition dollars to spend so much on this when there has to be a far more reasonable solution." One was worked out, simply by reducing the size of the room by a small amount. In all, the project director wore multiple hats, but key was that he was considered a member of the faculty with proven construction skills. 


\section{Must \#4}

Each initiative must identify the metrics to measure the intent against the results, ultimately demonstrating that the investment made was worth it. This is especially true in academe when the feedback loop on a project may be more than a year or two away. For the Stillman School, our measures of success were a combination of broad and specific ones. On a fairly high level, we wanted to see "students in the labs." Just the mere head count signaled that students and faculty were comfortable in using the facility. We hoped to increase the number of networking events for these rooms, bringing employers and practitioners to campus to use our facilities. We hoped to see our students participating in more competitions and competing for better jobs in their field. We hoped to see a larger range of employers come recruiting on campus. We sought to attract faculty with these laboratories. Initially, we hoped that the success of one laboratory would help faculty in other disciplines think about learning laboratories for their students. We hoped the laboratories would help us attract more students and a higher caliber of student. We sought to advance the school's good name with media stories about these laboratories and the faculty who worked in them. All of these measures would be indicators of success. Indeed, we report here that the school was successful in seeing terrific outcomes in all of these areas. Here are a few of the measurable results:

- $\quad$ The caliber of the students, as measured by SAT and GPA, improved.

- Their retention rate improved.

- $\quad$ Their job placement rate improved.

- $\quad$ The quality and variety of employers who recruited at Stillman increased.

- $\quad$ Students won external competitions.

- The quality of faculty hires increased.

- The donor base widened.

- $\quad$ Specialty scholarships and venture funds were created.

- $\quad$ Students launched new businesses.

- A student-run business newspaper was created.

- $\quad$ Sports polling results were reported internationally.

Beyond these "musts," we also point out that the Stillman School required, as would be expected for every large project, critical but basic blocking and tackling competencies for the successful launch of a learning laboratory.

One must have a budget. At Stillman, we had a simple, three-element budget before the contingency line item. These elements were:

1. Construction: Walls, doors, ceiling, and floor covering add to the major cost line item. For example, the number of power outlets for technology and the student laptops is rarely sufficient in standard building space, requiring more circuits and outlets installed. We often changed a wall to be glass and replaced the carpeting to a non-institutional look. Increased lighting for supporting video recording and microphone background noise were common problems easily solved but added to the expense. Our average cost per square foot remodeling was about $\$ 200$ and accounted for $50 \%$ of each budget. This cost included the cost of labor.

2. Furniture: Desks, file/storage cabinets, chairs, tables, credenzas, white boards, and other specific use items were purchased, whenever possible on university standard contracts and discounts, and were driven by the targeted number of work locations in each room averaging $\$ 4,300$ per work station and represented about $20 \%$ of each budget.

3. Technology: Network ports, cables, PC systems, sound systems, projectors, wall displays, and special functions equipment were less of an initial cost than expected. Software and data needs were a significant factor in the annual operating costs. All technology should be assumed to be in need of replacing after three years. Our average technology budget was $\$ 6,500$ and represented about $33 \%$ of each budget.

Second, one needs a detailed timeline plan with design and approval milestones dates plotted on Gantt Charts. These projects involve cross-department and cross-divisional decisions that are challenging in the best of 
circumstances. Microsoft Project or Excel provided the ability to show tasks by date with responsible party and approximate duration. Estimates should be assumed to be wrong unless provided by experienced individuals, which excludes most of the faculty. We found that targeting the summer sessions for construction was only possible if we started the planning process and engaged the university facilities management organization a year in advance.

Third, consideration must be given to the estimated useful life expectancy and the annual cost-ofownership. The build costs are significant, but the annual repeating burn can be just as significant with these special purpose labs. There is breakage, there are significant maintenance costs, and there is on-going training and student labor that needs some form of payment to stay engaged. Seven years is a long time for wear and tear. We have found the technology can last three years, the furniture five years, and the room itself seven years. The physical appearance of the room's rugs is the "tell" on when your laboratory needs a serious face-lift or may be retired.

\section{CONCLUSIONS}

Business schools need to be exemplars of the essence of their discipline. If business scholars extoll - and we do - the virtues of advancing quality, bringing about organizational change for the better and forming a connectedness between theory and practice, we have to emulate those values (Boyer, 1990). The learning laboratories at Stillman have been the vehicles to put into action those values, and, in the end, our students have benefitted.

\section{AUTHOR INFORMATION}

Professor Boroff is a member of the Department of Management at the Stillman School of Business at Seton Hall University. Her research interest in bringing about important organizational change via incremental approaches is inspired by her work as an instructor of Principles of Management and Organizational Behavior. E-mail: Karen.boroff@shu.edu (Corresponding author)

Professor Riley began his career teaching computer science at Ohio University followed by a research position at University of Illinois' Coordinated Science Laboratory. The use of technology led to investment banking applications on trading floors as well as clearing and settlement processes at a number of the largest global investment banks. Mr. Riley now teaches at the Stillman School of Business at Seton Hall University, in its department of finance. E-mail: Elven.riley@shu.edu

\section{REFERENCES}

1. $\quad$ Ardous, P. (2012). $21^{\text {st }}$ Century School, New Scientist, January, 42-5.

2. Barnes, K., Marateo, R., \& Ferris, S. P. (2008). Teaching and Learning with the Net Generation. innovate.

3. Boyer, E. L. (1990). Scholarship Reconsidered: Priorities of the Professorate. Princeton: Carneigie Foundation for the Advancement of Teaching.

4. Chaffee, E. E. (1984). Successful Strategic Management in Small Private Colleges. The Journal of Higher Education, 212-241.

5. Corbett, A. (2005). Experiential Learning Within the Process of Opportunity Identification and Exploitation. Entrepreneurship Theory and Practice, 473-91.

6. $\quad$ Dewey, J. (1938). Experience \& Education. New York: Kappa Delta Pi.

7. Hlebowitsh, P. S. (2009). Generational Ideas in Curriculum: an Historical Triangulation. In D. J. Flinders, \& S. J. Thornton, The Curriculum Studies Reader, 275-85, New York: Routledge.

8. Hubball, H., \& Gold, N. (2007). The Scholarship of Curriculum Practice and Undergraduate Program Reform: Integrating Theory into Practice. New Directions for Teaching and Learning, Winter 5 -14.

9. Kolb, A. Y., \& Kolb, D. A. (2005). Learning Styles and Learning Spaces: Enhancing Experiential Learning in Higher Education. Academy of Management Learning \& Education, Vol. 4, No. 2, 193-212.

10. Lester, W. F., \& Cole, J. A. (2009). Using a Financial Trading Room to Facilitate an Interdisciplinary, Learner-Centered Paradigm: One School's Experience. SBAJ, Spring, 44 - 57.

11. Lindquist, J. (1978). Strategies for Change. Berkeley: William Bergquist. 
12. Mangan, K. (2012). At Meeting, Federal Judge Hands Down a Sharp Opinion About Law Schools, The Chronicle of Higher Education, January 8.

13. Tyler, R. W. (1949). Basic Principles of Curriculum and Instruction. Chicago: The University of Chicago Press.

14. Reder, M. (2010). Effective Practices in the Context of Small Colleges. In K. Gillespie, \& D. Robertson, $A$ Guide to Faculty Development (pp. 293 - 308). San Francisco: John Wiley \& Sons.

15. Summers, L. H. (2012). The 21st Century Education, The New York Times Education Life, January 22 , $26+$.

16. Tushman, M. L., \& Scanlan, T. J. (1981). Boundary Spanning Individuals: Their Role in Information Transfer and Their Antecedents. Academy of Management Journal, 289-305.

17. Tyler, R. W. (1949). Basic Principles of Curriculum and Instruction. Chicago: The University of Chicago Press.

18. Wolf, P. (2007). A Model for Facilitating Curriculum Development in Higher Education: A FacultyDriven, Data-Informed, and Educational Developer-Supported Approach. New Directions for Teaching and Learning, Winter, 15 -20. 
NOTES 